Fig1. Change of Mean Values and P-value during bDMARDs Treatment in RA Patients

\begin{tabular}{|l|c|c|c|c|c|c|}
\hline & Baseline & $\mathbf{1}$ month & $\mathbf{3}$ months & $\mathbf{6}$ months & $\mathbf{1 2}$ months & $\mathbf{2 4}$ months \\
\hline SDAl & 19.0 (Cont.) & $9.8(<0.01)$ & $6.7(<0.01)$ & $6.3(<0.01)$ & $5.5(<0.01)$ & $4.7(<0.01)$ \\
\hline CRP (mg/dl) & 2.1 (Cont.) & $0.7(<0.01)$ & $0.8(<0.01)$ & $0.7(<0.01)$ & $0.4(<0.01)$ & $0.1(<0.01)$ \\
\hline Grasping Power (kg) & 11.9 (Cont.) & $13.2(0.08)$ & $14.4(<0.01)$ & $15.4(<0.01)$ & $16.6(<0.01)$ & $18.3(<0.01)$ \\
\hline KEP (N/kg) & 3.0 (Cont.) & $3.1(0.11)$ & $3.3(0.08)$ & $3.5(<0.01)$ & $3.7(<0.01)$ & $3.9(<0.01)$ \\
\hline TUG (second) & 9.1 (Cont.) & $8.2(0.055)$ & $8.2(<0.05)$ & $7.4(<0.01)$ & $7.6(<0.05)$ & $7.5(<0.01)$ \\
\hline $10 \mathrm{~mW}$ (second) & 8.0 (Cont.) & $7.5(0.0503)$ & $7.4(0.26)$ & $6.8(<0.01)$ & $6.8<0.01)$ & $6.9(<0.01)$ \\
\hline mHAQ & 0.48 (Cont.) & $0.40(0.12)$ & $0.24(<0.01)$ & $0.26(<0.01)$ & $0.20(<0.01)$ & $0.22(<0.05)$ \\
\hline Locomo25 & 29.1 (Cont.) & $21.1(0.02)$ & $18.4(<0.01)$ & $18.9(<0.01)$ & $16.0(<0.01)$ & $15.0(<0.01)$ \\
\hline Fall risk index & 8.5 (Cont.) & $8.4(0.61)$ & $7.8(0.13)$ & $8.0(0.25)$ & $7.1(<0.01)$ & $7.2(<0.05)$ \\
\hline
\end{tabular}

Data is expressed as mean (p-value). P-value was caluculated using Wilcoxon signed-rank test between baseline and each month.

SDAl: simplified disease activity index, KEP: knee extention power, TUG: timed up and go test, $10 \mathrm{~mW}: 10 \mathrm{~m}$ walking time, $\mathrm{mHAQ}$ : modified health assessment questionnaire

Conclusion: Although there was a rapid improvement in the signs and symptoms of RA after the initiation of bDMARD treatment, improvement in PF was slightly delayed. Significant improvement of muscle power and agility was achieved after 3-6 months onward. Inhibition of fall risk was achieved at and after 12 months after the initiation of bDMARD treatment. These results suggest that physiotherapy plays a vital role in RA patients who undergo treatment with bDMARDs to gain more rapid improvement of PF.

References:

[1] Smolen JS et al. Ann Rheum Dis, 2016.

[2] Hirano Y et al. Ann Rheum Dis, suppl. 2, 2019.

[3] Toba K et al. Jpn J Geriat, 2005.

[4] Seichi A at al. J Orthop Sci, 2012.

Disclosure of Interests: Yuji Hirano Speakers bureau: Tanabe-Mitsubishi, Pfizer, Eisai, Abbie, Chugai, Bristol-Meyers, Jansen, Astellas, UCB, Eli-Lilly, Asahikasei, Daiichi-Sankyo, Amgen, Ayako Morisaka: None declared, Hironobu Kosugiyama: None declared, Shiori Inuzuka: None declared, Takeshi Kamiya: None declared, Hiroyuki Mori: None declared, Naohito Morishima: None declared, Tomoji Ishikawa: None declared

DOI: 10.1136/annrheumdis-2020-eular.2306

\section{FRI0098 ASSOCIATION BETWEEN THE SEROLOGIC STATUS OF ISOTYPE-SPECIFIC AUTOANTIBODIES AND THERAPEUTIC EFFICACY IN RHEUMATOID ARTHRITIS PATIENTS TREATED WITH ABATACEPT: A PROSPECTIVE ULTRASOUND COHORT STUDY IN JAPAN}

S. Y. Kawashiri ${ }^{1,2}$, Y. Endo ${ }^{1,2}$, A. Nishino ${ }^{2}$, T. Shimizu ${ }^{1,2}$, Y. Ueki $^{2}$, N. Eiraku ${ }^{2}$, A. Okada ${ }^{2}$, N. Matsuoka ${ }^{2}$, T. Yoshitama ${ }^{2}$, H. Nakamura ${ }^{1,2}$, M. Tamai $^{1}$, T. Origuchi ${ }^{1,2}$, R. Toes $^{3}$, T. Huizinga ${ }^{3}$, A. Kawakami ${ }^{1}{ }^{1,} .{ }^{1}$ Nagasaki University Graduate School of Biomedical Sciences, Department of Immunology and Rheumatology, Nagasaki, Japan; ${ }^{2}$ Kyushu Multicenter Rheumatoid Arthritis Ultrasound Prospective Observational Cohort Study Group, Nagasaki, Japan ${ }^{3}$ Leiden University Medical Center, Department of Rheumatology, Leiden, Netherlands

Background: The presence of anti-cyclic citrullinated protein antibodies (ACPA) and anti-carbamylated protein (anti-CarP) antibody is specific for rheumatoid arthritis (RA). Recently, it was reported that the serological status of ACPA is associated with the therapeutic response of the T-cell co-stimulation blocker abatacept $(1,2)$. However, it is currently unclear whether the serological status of each isotype levels of these autoantibodies before treatment introduction or the changes during treatment are associated with the therapeutic response of abatacept.

Objectives: To evaluate longitudinal changes in the isotypes of ACPA and antiCarP in RA patients treated with abatacept, and associations between the baseline serological status/ these changes and clinical response/ ultrasonographic response.

Methods: This study is part of an ongoing non-randomized multicenter prospective cohort study of patients with active RA who received biological or targeted DMARD therapy at 13 participating rheumatology centers from the Kyushu region of Japan since June 2013 (3). As of the present report, we enrolled 43 consecutive Japanese patients with active RA who have introduced treatment with abatacept and had finished the first 12-month observation period. We evaluated disease activity by clinical composite measure and ultrasound score at baseline, 3, 6, 9 and 12 months. In ultrasound of bilateral hands from 22 sites, the findings obtained by gray-scale (GS) and power Doppler (PD) assessments were graded on a semi-quantitative scale from 0 to 3 and the sum of GS or PD scores was used as the total GS or PD score. The serum levels of $\mathrm{IgG} / \mathrm{IgM} / \mathrm{IgA}$-type of ACPA and anti-CarP were measured by the ELISA method in Leiden University Medical Center. We evaluated the association between serologic status of autoantibodies and clinical /ultrasonographic therapeutic efficacy.

Results: The median age was 72 years, and the disease duration was 54 months. Methotrexate was concomitant in $22(51 \%)$. Sixteen $(37 \%)$ patients had a history of previous use of biological DMARDs. Nineteen $(44 \%)$ and 23 (54\%) patients achieved SDAI remission and PD remission (total PD score $=0)$ at 12 months, respectively. The serum levels of all isotypes of ACPA/antiCarP significantly decreased at 12 months from baseline. The reduction of IgM-ACPA level significantly correlated with the reduction of SDAI ( $r s=0.33$, $p=0.031)$ and total PD score ( $r s=0.49, p=0.0007)$. Both clinical and ultrasonographic therapeutic responses were better in patients with the detectable IgMACPA at baseline than in patients without that (Figure): the reduction of SDAI $(p=0.0078)$ and that of total PD score $(p=0.0079)$ were significantly larger in the former than in the latter. All isotype of anti-CarP did not associate with therapeutic response.

Conclusion: Treatment of abatacept induced to the reduction of the autoantibody levels. The IgM-ACPA level at baseline and the change in IgM-ACPA associated with both clinical and ultrasonographic therapeutic response in patients treated with abatacept. IgM-ACPA, compared with usual IgG-ACPA, better reflects the treatment response of abatcept in patients with $\mathrm{RA}$

References:

[1] Ann Rheum Dis. 2016;75:709, 2) RMD Open. 2018;4:e000564, 3)Arthritis Care Res (Hoboken). 2018;70:1719.

Figure 1. Clinical and ultrasonographic response in patients with the detectable IgM-ACPA at baseline $(A)$ than in patients without that $(B)$

(A)

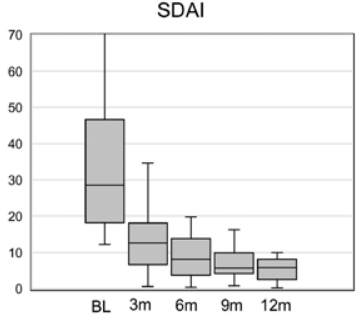

SDAI

B)
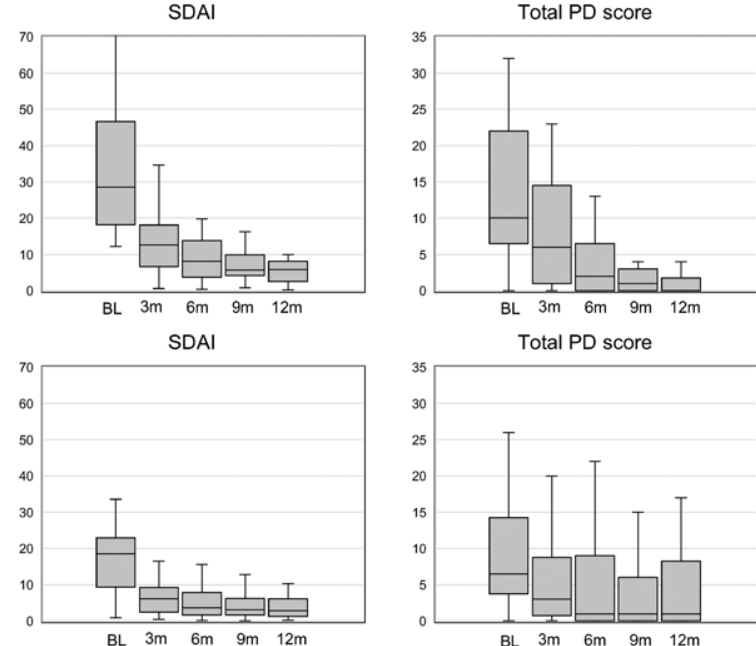

Total PD score

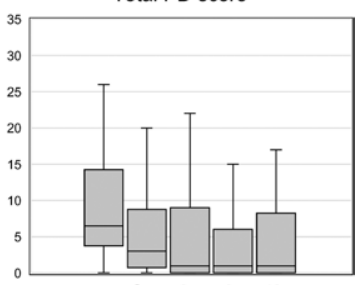

BL $3 \mathrm{~m} \quad 6 \mathrm{~m} \quad 9 \mathrm{~m} \quad 12 \mathrm{~m}$

Acknowledgments: We have acknowledged for all the members of Kyushu multicenter rheumatoid arthritis ultrasound prospective observational cohort study group.

Disclosure of Interests: Shin-ya Kawashiri Grant/research support from: This work was supported by Bristol-Myers Squibb and Ono Pharmaceutical. co., Yushiro Endo: None declared, Ayako Nishino: None declared, Toshimasa Shimizu: None declared, Yukitaka Ueki: None declared, Nobutaka Eiraku: None declared, Akitomo Okada: None declared, Naoki Matsuoka: None declared, Tamam Yoshitama: None declared, Hideki Nakamura: None declared, Mami Tamai: None declared, Tomoki Origuchi: None declared, Rene Toes: None declared, Thomas Huizinga Grant/research support from: Ablynx, Bristol-Myers Squibb, Roche, Sanofi, Consultant of: Ablynx, Bristol-Myers Squibb, Roche, Sanofi, Atsush Kawakami: None declared

DOI: 10.1136/annrheumdis-2020-eular.2269

\begin{tabular}{l|l}
\hline FRI0099 & THE IMPACT OF BIOLOGICAL DISEASE-MODIFYING \\
& ANTI-RHEUMATIC DRUGS ON THE COURSE OF \\
& RHEUMATOID ARTHRITIS-ASSOCIATED LUNG \\
& DISEASE
\end{tabular}

A. Köken Avșar ${ }^{1}$, G. Can ${ }^{1}$, M. Birlik ${ }^{1}$, I. Sari ${ }^{1}$, F. Onen ${ }^{1} .{ }^{1}$ Dokuz Eylul University Medical School, Rheumatology Department, Izmir, Turkey 